\title{
Perceptions of Trained Leaders on Improving the Public Health Impact of Three Arthritis Foundation Programs
}

Danielle R. Brittain, PhD

Nancy C. Gyurcsik, PhD

The Arthritis Foundation (AF) offers effective communitybased programs to help manage arthritis, including aquatic, exercise, and self-help programs. Trained leaders can facilitate the adoption, maintenance, and reach of these programs and thus the impact on public health. This study identifies reasons for becoming AF aquatic, exercise, and/or self-help program leaders, AF program reach, and adoption and maintenance challenges encountered by individuals after being trained. Researchers interviewed by telephone 72 participants who attended an AF leader training workshop. Participants reported various reasons for becoming program leaders (e.g., a wish to help others). AF programs were mainly adopted and maintained in urban communities and in fitness/ health clubs, medical centers, or senior centers. Aquatics programs were the most frequently offered, and all programs had low reach (with a mean number of participants of $14.41,12.50$, and 11.00 for aquatic programs, exercise programs, and self-help programs, respectively. Challenges to adopting and maintaining programs include the time of year (e.g., winter, holidays) and lack of a facility to offer the program.

Keywords: arthritis; physical activity; education; leaders; public health

$\mathrm{D}$ octor-diagnosed arthritis affects 46.4 million adult Americans, with 17.4 million of these individuals reporting arthritis-attributable activity limitations (Freedman, Hootman, \& Helmick, 2007). Because no cure exists for the more than 100

Health Promotion Practice

July 2010 Vol. 11, No. 4, 572-579

DOI: $10.1177 / 1524839908328997$

(C2010 Society for Public Health Education different types of arthritis, recommended management strategies include medication, surgery, regular participation in moderate physical activity, and education (Arthritis Foundation, Association of State and Territorial Health Officials, \& Centers for Disease Control, 1999; Boutaugh \& Brady, 1996; Minor, Stenstrom, Klepper, Hurley, \& Ettinger, 2003). In regard to physical activity and education for people with arthritis, the Arthritis Foundation offers a variety of programs in communities across the country. For this study, two physical activity programs and one educational program offered by a state chapter of the Arthritis Foundation were the focus.

The first of these programs was the Arthritis Foundation Aquatics Program (AFAP), which is a 6-8week water-based physical activity program that meets twice per week and includes basic range of motion and muscle strengthening exercises, as well as optional endurance-building exercises (Arthritis Foundation, 2007). The second program was the Arthritis Foundation Exercise Program (AFEP), a 6-8-week land-based physical activity program meeting twice per week and including flexibility, range of motion, and muscle strengthening exercises. The third program was the Arthritis Foundation Self-Help Program (AFSHP), a 6week educational program that meets twice per week and includes a variety of components, such as basic information on disease, relaxation techniques to manage pain, an overview of arthritis medications, and techniques for coping with depression.

All three programs, AFAP, AFEP, and AFSHP, are effective in improving the health of participants

Authors' Note: This research was supported through a contract awarded by a state Department of Health and Environment. The authors thank Angela Deines and Cindy Winters for their assistance. Please address correspondence concerning this article to Danielle R. Brittain, 1401 Asp Avenue, Norman, OK 73019; e-mail: dbrittain@ou.edu. 


\section{The Authors}

Danielle R. Brittain, PhD, is an Assistant Professor in the Department of Health and Exercise Science at the University of Oklahoma in Norman, Oklahoma.

Nancy C. Gyurcsik, PhD, is an Associate Professor in the College of Kinesiology at the University of Saskatchewan in Saskatoon, Saskatchewan, Canada.

(Boutaugh, 2003; Boutaugh \& Brady, 1996). For example, participation in AFAP resulted in decreased pain and improved performance of activities of daily living, and participation in AFEP was associated with improved functional ability and decreased depression. Furthermore, participation in AFSHP resulted in decreased pain and depression. Because of the positive health outcomes associated with regular participation in AFAP, AFEP, or AFSHP, a need exists to increase the public health impact of these programs among adults with arthritis (Boutaugh, 2003; Glasgow, Vogt, \& Boles, 1999).

According to the framework developed by Glasgow et al. (1999), five factors should be considered when evaluating the public health impact of health programs: reach, effectiveness, adoption, implementation, and maintenance (RE-AIM). Reach is the absolute number, proportion, and representativeness of individuals who participate in an effective health promotion program compared with the priority population. Effectiveness is the success of the program in affecting health behavior and associated health outcomes in real-world settings. Adoption is the absolute number, proportion, and representativeness of settings or organizations that offer the health promotion program. Implementation refers to whether a program is delivered as intended. Maintenance is the level of sustained individual behavior and organizational use of the program over time.

Typically, not all five dimensions of the RE-AIM framework are assessed in the same research study, with reach and effectiveness being most frequently assessed (Glasgow et al., 1999; Glasgow, Nelson, Strycker, \& King, 2006). Among research in arthritis programming, Gyurcsik and Brittain (2006) partially examined the public health impact of AFEP through a focus on reach, adoption, and maintenance of the program in a midwestern state. Conclusions were that the public health impact of AFEP was low in the state because of low program reach and maintenance. That is, in addition to the small number of program participants (i.e., low reach), the majority of individuals who were trained to lead AFEP did not continue to offer the program in community-based sites over time (i.e., low maintenance). The problem of leaders' discontinuing the offering of community-based health programs has been found in other research involving other types of communitybased health programs (e.g., Bopp et al., 2007).

Clearly, leaders are a key element in the successful translation and maintenance of community-based health programs and thus should be focused on (Bopp et al., 2007; Estabrooks \& Gyurcsik, 2003; Glazier, Bajcar, Kennie, \& Willson, 2006; Gyurcsik \& Brittain, 2006; Schoster, Callahan, Meier, Mielenz, \& DiMartino, 2005; Seguin et al., 2008). In particular, for effective arthritis-specific programs (i.e., AFAP, AFEP, and AFSHP) to be adopted and maintained within and across communities, individuals must first be recruited and trained to lead these programs through Arthritis Foundation workshops. Only when individuals are trained do programs have the potential to be adopted and maintained in the community. Once programs are adopted and maintained, their reach may be improved because more opportunities are provided for adults with arthritis to participate.

In order for individuals to be fully trained to lead AFAPs, AFEPs, or AFSHPs, three tasks must be completed. First, individuals must attend an 8- to 10-hour AFAP, AFEP, or AFSHP leader training workshop offered by the Arthritis Foundation. Second, within 6 months after completion of the workshop, individuals must offer the program they were trained to lead, which typically encompasses classes 2 days per week for 6-8 weeks. Third, individuals can then become certified leaders by completing and submitting a certification application and a class roster to the Arthritis Foundation. After 3 years of being a certified leader, individuals are required to attend a half-day of refresher training offered by the Arthritis Foundation.

Because trained leaders are needed for the AFAP, AFEP, and AFSHP, research on the experience of leaders, which may be amenable to change, is necessary to provide insight into strategies for increasing the reach, adoption, and maintenance of these effective arthritis-specific programs (cf. Bopp et al., 2007; Estabrooks \& Gyurcsik, 2003; Schoster et al., 2005). Thus, the current study had three objectives. The first study objective was to determine the reason(s) individuals were interested in becoming leaders of AFAP, AFEP, and/or AFSHP and, in relevant situations, the reason(s) individuals did not pursue certification after attending the Arthritis Foundation leader training workshops. Knowing these reasons could lead to a greater public health impact of AFAPs, AFEPs, and AFSHPs in that the Arthritis Foundation could target 
individuals with specific motivations to attend leader training workshops. The workshops could also contain content that addresses challenges to leader certification.

The second study objective was to determine the location, number of participants, and total number of sessions taught by individuals since being trained to lead AFAPs, AFEPs, or AFSHPs. Location information provided the geographic locale of these programs (i.e., adoption location). The total number of participants provided information on the reach of AFAPs, AFEPs, and AFSHPs. The total number of sessions taught by leaders provided information on the continued offering (i.e., maintenance) of AFAPs, AFEPs, and AFSHPs.

The third study objective was to determine the challenges encountered by leaders who attempted to adopt AFAPs, AFEPs, or AFSHPs in their local communities. Such challenges to program adoption could be alleviated in the future through targeted discussions at leader training workshops, and as a result, the number of AFAPs, AFEPs, and AFSHPs offered to adults with arthritis could be enhanced. As part of the third objective, the types of support that leaders preferred to receive from the state chapter of the Arthritis Foundation in adopting or maintaining AFAPs, AFEPs, and AFSHPs were examined.

\section{METHOD}

\section{Participants}

Participants were 72 adults with a mean age of 49.14 years $(S D=11.59$ years); 69 participants were women, and 3 participants were men. The majority of participants were White $(n=69)$ and employed in various occupations, with the most frequent occupations being aquatics instruction $(n=12)$ and fitness class instruction $(n=12)$. Other occupations included homemaker $(n=6)$; health educator $(n=5)$; nurse $(n=4)$; and physical, occupational, or recreation therapist $(n=4)$. The rest of the participants cited a variety of other occupations (Table 1). Participants attended at least one leader training workshop: AFAP $(n=50)$, AFEP $(n=7)$, AFAP and AFEP $(n=7)$, AFSHP $(n=4)$, AFAP and AFSHP $(n=2)$, AFEP and AFSHP $(n=1)$, and all three programs $(n=1)$; 1 participant did not respond to this question.

\section{Procedures}

To achieve the study objectives, four procedures were followed. First, a survey was developed by personnel of the Arthritis Program at a midwestern state Department of Health, the state's Arthritis Steering Committee, and the university-based principal investigator of the study.

\begin{tabular}{lc}
\multicolumn{2}{c}{ TABLE 1 } \\
Occupations of the Participants \\
\hline Occupation & No. Participants \\
(N $=72)$ \\
\hline Aquatics instructor & 12 \\
Fitness instructor & 12 \\
Homemaker & 6 \\
Retired & 6 \\
Health educator & 5 \\
Nurse & 4 \\
Physical/occupational/recreation therapist & 4 \\
Fitness center employee & 3 \\
School teacher & 2 \\
Social worker & 2 \\
Telecommunications & 2 \\
Other & 14 \\
\hline
\end{tabular}

NOTE: Occupations in the "other" category were cited once each.

The survey was designed to be administered via the telephone by trained staff at the state Department of Health. The questions sought data to address each of the study objectives, as well as demographic information. The number of questions asked each participant varied depending on the leader training workshops the participant had attended (i.e., AFAP, AFEP, and/or AFSHP) and the participant's pattern of answering (e.g., yes to a question vs. no to a question).

Second, the state chapter of the Arthritis Foundation provided a list, which included the contact information of individuals who had attended at least one AFAP, AFEP, or AFSHP leader training workshop in the state during the preceding 17 years, ${ }^{1}$ to the Arthritis Program at the state Department of Health. Third, following institutional review board approval, trained interviewers at the state Department of Health telephoned each individual on the list. On contact, each individual was informed that a telephone survey was being conducted by the Arthritis Program at the state Department of Health and the statewide Arthritis Steering Committee, in conjunction with the state chapter of the Arthritis Foundation, to obtain information on individuals who had attended at least one AFAP, AFEP, or AFSHP leader training workshop. Individuals were informed that they were free not to answer any question, the interview could be stopped at any time without negative consequence, and the interview would take approximately $15 \mathrm{~min}$ to complete. With verbal consent from the participant, the survey was administered, and the trained interviewer recorded the participant's responses on a survey. Fourth, the 
TABLE 2

Response Frequencies for Reasons One Was Interested in Becoming a Leader

\begin{tabular}{|c|c|c|c|c|c|c|c|c|}
\hline Reason & $\begin{array}{c}\text { All } \\
\text { Leaders } \\
\text { (no.) }\end{array}$ & $\begin{array}{l}\text { Only } \\
\text { AFAP } \\
\text { (no.) }\end{array}$ & $\begin{array}{l}\text { Only } \\
\text { AFEP } \\
\text { (no.) }\end{array}$ & $\begin{array}{c}\text { Only } \\
\text { AFSHP } \\
\text { (no.) }\end{array}$ & $\begin{array}{c}A F A P \& \\
A F E P \\
\text { (no.) }\end{array}$ & $\begin{array}{c}A F A P \& \\
A F S H P \\
\text { (no.) }\end{array}$ & $\begin{array}{c}A F E P \mathcal{E} \\
A F S H P \\
\text { (no.) }\end{array}$ & $\begin{array}{c}\text { AFAP, } \\
\text { AFEP, \& } \\
\text { AFSHP (no.) }\end{array}$ \\
\hline Other reason & 42 & 28 & 3 & 2 & 5 & 2 & 1 & 1 \\
\hline $\begin{array}{l}\text { Wanted to give back to the } \\
\text { community }\end{array}$ & 25 & 17 & 1 & 3 & 2 & 2 & 0 & 0 \\
\hline Job requirement & 22 & 14 & 3 & 2 & 2 & 0 & 0 & 1 \\
\hline $\begin{array}{l}\text { Enjoyment and/or } \\
\text { satisfaction }\end{array}$ & 12 & 10 & 0 & 0 & 0 & 2 & 0 & 0 \\
\hline Have arthritis & 12 & 8 & 1 & 1 & 1 & 1 & 0 & 0 \\
\hline $\begin{array}{l}\text { Participated in a class and } \\
\text { it helped me }\end{array}$ & 6 & 4 & 0 & 1 & 0 & 1 & 0 & 0 \\
\hline $\begin{array}{l}\text { Hoped it would help get } \\
\text { a job }\end{array}$ & 2 & 1 & 1 & 0 & 0 & 0 & 0 & 0 \\
\hline Total & 121 & 82 & 9 & 9 & 10 & 8 & 1 & 2 \\
\hline
\end{tabular}

NOTE: AFAP = Arthritis Foundation Aquatics Program; AFEP = Arthritis Foundation Exercise Program; AFSHP = Arthritis Foundation Self-Help Program.

Arthritis Program of the state Department of Health provided the completed surveys to the principal investigator of the study. Data were entered into SPSS version 15.0 and subsequently analyzed.

\section{RESULTS}

Objective 1 was to determine the reason(s) individuals were interested in becoming leaders of AFAPs, AFEPs, or AFSHPs and, in certain cases, the reason(s) individuals did not pursue certification after attending the Arthritis Foundation leader training workshops. Table 2 contains the reasons individuals were interested in becoming leaders of the AFAP, AFEP, or AFSHP. For all the leaders combined, the open-ended response category of "other reasons" was cited most frequently $(n=42)$. Some of other reasons cited were work related, such as "an instructor was needed at work so the individual volunteered," "complemented existing employment in massage or occupational therapy," and "a wish to help people with arthritis feel better." Other frequently cited reasons included "wanting to give back to the community" ( $n=$ $25)$ and "a job requirement" $(n=22)$. The least frequently cited reasons were "hoping that becoming a leader would help one gain employment" $(n=2)$ and "having participated in a class" $(n=6)$. Similar trends were observed when the responses of AFAP, AFEP, and AFSHP leaders were examined independently.

Nine $(12.5 \%)$ of the 72 participants had attended an Arthritis Foundation leader-training workshop but had not obtained certification at the time of assessment. Of the 9 participants, 6 attended an AFAP leader-training workshop, 2 attended an AFEP leader-training workshop, and 1 attended both an AFAP and an AFEP leader-training workshop. Three individuals were in the process of completing the certification requirement of offering a program. Two additional individuals had led a program and were in the process of sending the appropriate paperwork to the Arthritis Foundation. Thus, a total of 5 individuals were still pursuing certification. In addition, the following reasons were given for not obtaining certification: (a) One individual reported a bad experience with an AFAP leader-training workshop that did not take place until 6-8 months after registration, (b) another reported taking the workshop for continuing education credits only, (c) another said the Arthritis Foundation did not inspect the hospital where the program was occurring, ${ }^{2}$ and (d) the fourth reported not passing the cardiopulmonary resuscitation test, which was required at the setting where the program was to be offered.

Objective 2 was to determine the location (i.e., adoption location), number of participants (i.e., reach), and total number of sessions taught (i.e., maintenance) by individuals since being trained to lead AFAPs, AFEPs, or AFSHPs. In all, 49 (68\%) of the 72 participants were leading an AFAP (i.e., a total of 49 programs) at 30 different sites across 17 different communities at the time of the survey. Of the 49 programs, 18 (37\%) were located in communities with a population less than 
50,000 , and the remaining 31 programs (63\%) were being offered in communities with a population of more than 50,000. The programs were being conducted primarily in fitness or health clubs, medical or health centers, senior and community centers, and senior residence facilities.

At the time of assessment, 9 (13\%) of the 72 participants were leading an AFEP (i.e., a total of nine programs) at six different sites across six different communities. Three of the nine programs (33\%) were taking place in communities with a population less than 50,000, and the remaining six programs $(67 \%)$ were taking place in communities of more than 50,000 people. AFEP programs were primarily conducted in senior centers, nursing homes, senior residence facilities, and medical or health centers. Of the nine instructors leading an AFEP, three instructors (33\%) were also leading an AFAP.

In regard to the AFSHP, 2 of the 72 participants (3\%) were each leading a program in two different communities. Both communities had a population less than 50,000 . One program took place in a hospital, and the other program took place in a recreation center. The 2 instructors were not engaged in leading either of the other Arthritis Foundation programs of interest in the study (i.e., AFAP or AFEP).

To assess the maintenance of AFAPs, AFEPs, and AFSHPs, respondents were asked the total number of sessions they taught since being trained. On average, AFEP leaders offered $257.75(S D=490.38)$ sessions, which equates to 22 six-week or 16 eight-week courses. AFAP leaders offered an average of 175.87 ( $S D=$ 337.83) sessions, which is almost 15 six-week or 11 eight-week courses. AFSHP leaders offered an average of 86.00 ( $S D=184.48)$ sessions, which equates to 7 six-week courses.

The reach of AFAPs, AFEPs, and AFSHPs was assessed from each leader's indication of the average number of participants who attended their Arthritis Foundation-sponsored program. On average, 14.41 (SD = 9.10) people attended the AFAPs, followed by an average of $12.50(S D=3.47)$ people in AFEPs and 11.00 $(S D=3.94)$ people in the AFSHPs.

Objective 3 was to determine the (a) challenges encountered by leaders who attempted to start AFAPs, AFEPs, or AFSHPs and (b) preferred types of support from the state chapter of the Arthritis Foundation. Challenges that completely precluded trained individuals from attempting to begin a program in their local communities as well as challenges that prevented trained individuals from beginning a program despite attempts to do so were examined. Very few participants $(n=6)$ provided challenges that completely precluded them from attempting to begin a program in their local communities. One individual trained to lead AFAPs indicated that the time of year (i.e., holidays/winter) was not ideal for beginning a new class. Another trained leader indicated that the lack of a facility to host an AFAP was the reason for not attempting to start a program in the local community. In terms of challenges that prevented attempts to begin AFEPs, 1 participant stated a lack of time due to employment, and another stated that the director of the fitness center where the participant was employed did not perceive a need for an AFEP. Similarly, 1 participant trained to lead AFSHPs indicated the barrier of a lack of time due to employment, while another indicated responsibility for conducting AFSHPs as a substitute leader only and thus not having to start an AFSHP.

A total of 5 participants reported challenges that prevented them from beginning a program in their local community despite their attempts to do so (i.e., these individuals tried to start a program but failed to do so). Specifically, 1 stated that an AFAP was not adopted because of the time of year the program was beginning (i.e., at holiday time, when potential participants are not motivated to join the program), while 3 participants indicated they had taken over an existing class (i.e., did not have to start a class). Furthermore, 1 participant indicated the AFEP was not adopted because the host site was under reconstruction.

All participants indicated the types of support they would prefer to receive from the local chapter of the Arthritis Foundation when adopting or maintaining AFAPs, AFEPs, or AFSHPs in their local communities. Analysis of the data revealed no differences between the responses provided by the leaders of AFAPs, AFEPs, or AFSHPs. Therefore, to present the data, all responses were combined. Participants most frequently expressed a preference for the following support strategies: a newsletter to provide program updates or changes $(n=27)$, standardized program promotional material $(n=21)$, and site visits provided by the Arthritis Foundation $(n=10)$, as well a listserver or e-mail ( $n=$ 12 ) and annual or biannual meetings $(n=10)$. The purpose of the listserver, e-mail, and meetings would be for leaders to stay connected with staff at the Arthritis Foundation and for leaders to stay informed. Participants also indicated the importance of continuing education (e.g., to learn about specific types of exercises for specific types of arthritis; $n=6$ ), aid in the identification of a host site $(n=4)$, regular leader certifications and recertifications $(n=4)$, and the provision of educational material on arthritis and related exercises for the participants $(n=2)$. Four participants were satisfied with the current level of support from the Arthritis Foundation. 


\section{DISCUSSION}

The first objective of the study was to identify reasons individuals were interested in becoming leaders of AFAPs, AFEPs, or AFSHPs, as well as reasons individuals did not pursue leader certification. The majority of participants were trained to lead AFAPs, and only 11 were trained to lead AFEPs or AFSHPs. The most frequently reported reasons for becoming a leader, across AFAPs, AFEPs, and AFSHPs, were work related (e.g., an instructor was needed at work or becoming a leader complemented existing employment as a therapist) and a wish to help others. Wanting to give back to the community was also frequently cited by the participants. In contrast, Hainsworth and Barlow (2001) found the primary reasons that older adults (median age, 58 years) became volunteer leaders of a United Kingdom-based arthritis self-management course (same program as AFSHP) were different from those identified in this study. The participants in the Hainsworth and Barlow study became leaders because of having previous class experience as a participant, wanting to fill a vocational need that arose because of retirement and an associated loss of intellectual challenge, and finding that being a leader provided a sense of direction and a purposeful activity. Considering that the majority of our sample was younger and employed, whereas the Hainsworth and Barlow sample was primarily older and retired, distinct differences may exist in the reasons individuals in different age groups choose to become leaders of Arthritis Foundation programs. Thus, because of the potentially different motivations for becoming leaders across age groups, recruitment materials may need to be targeted to specific age groups to stimulate their interest in becoming leaders.

Based on these results, a need exists to increase the total number of trained AFEP and AFSHP leaders. One strategy to actively engage and motivate individuals to become leaders may involve targeting places of employment where AFEP and AFSHP can be offered. For example, targeted recruitment material sent to fitness or health clubs, medical or health centers, and senior centers may prove beneficial. In a separate study, O'Loughlin, Renaud, Richard, Gomez, and Paradis (1998) found community-based interventions promoting heart health were likely to be maintained when run by nonpaid volunteers. Based on this latter finding, another strategy may be to target nonpaid volunteers at service organizations, such as churches and community centers, which focus on caregiving and helping others. The combination of targeting individuals in employment settings and at service organizations could lead to more individuals' becoming trained to lead AFEPs and AFSHPs, thereby increasing the number of these health-enhancing programs offered to adults with arthritis. Another strategy may be to enlist appropriate employers and service organizations in identifying potential leaders. This could be done by distributing leader-training announcements describing the benefits to the place of employment or service organization of an in-house AF program. For example, a benefit to a fitness center may be an increase in the number of individuals who buy a membership because of the offering of an AFEP. Benefits to a service organization may be an increase in the number of individuals who are served, as well as increased public exposure for the organization.

The majority of our study participants were fully certified leaders or in the process of completing certification. Only 4 individuals did not pursue certification after attending a leader-training workshop. These participants did not pursue certification for a variety of reasons, described earlier. One of those reasons, the length of time between registration and the actual occurrence of the leader-training workshop, is the most amenable to change and thus should be targeted for change (cf. Bopp et al., 2007). For example, future leader-training workshops should be conducted by the Arthritis Foundation shortly after the registration deadline.

The second study objective was to determine the location, number of participants, and total number of sessions taught by individuals since being trained to lead AFAPs, AFEPs, or AFSHPs. Overall, sites were primarily offering AFAPs in communities with a population more than 50,000. Only eight AFEP locations were identified, with five programs in communities of more than 50,000 and three in communities with a population less than 50,000. Only two sites offered the AFSHP, and both sites were in communities with a population less than 50,000. Overall, the majority of programs were offered in urban rather than rural communities.

Because of the relatively low numbers of AFEPs and AFSHPs, efforts should be made to increase the number of trained leaders, through regular leader certifications, as well as to increase the number of sites in rural and urban communities that adopt and maintain these programs. Efforts should also target an increase in the adoption and maintenance of AFAPs in rural communities. Such efforts may be more difficult because a community must have a pool, and the temperature of the pool is required by the Arthritis Foundation to be at least $83^{\circ} \mathrm{F}$ (Arthritis Foundation, 1996). By promoting the adoption and maintenance of AFAPs, AFEPs, and AFSHPs across rural and urban sites, the total number of adults with arthritis who can participate and achieve 
health benefits should increase (Wilcox et al., 2006). Recall that the average number of participants at AFAPs, AFEPs, or AFSHPs in our study ranged from 11 to almost 15. Although increasing participation rates could also be targeted as a way to increase reach if more programs were offered, more adults with arthritis could have the opportunity to participate. For example, offering 20 additional AFEP classes could benefit approximately 300 additional adults with arthritis (based on the average AFEP attendance rate from this study).

The third study objective examined the challenges encountered by leaders in attempts to adopt AFAPs, AFEPs, or AFSHPs in their local community. Only a small number of participants reported challenges. The primary challenges included an inconvenient time of the year for the program to be offered (e.g., holiday time), which is similar to results found in previous research (Gyurcsik \& Brittain, 2006). Other challenges included the lack of a facility to host the program and the lack of support from the fitness facility director. Recommendations are to focus on alleviating challenges most controllable and salient. For example, during AFAP, AFEP, and AFSHP leader training workshops, attempts to initiate the program during holiday times (e.g., Thanksgiving and Christmas) should be discouraged. In contrast, attempts to begin the program during times when individuals are likely more motivated to change should be encouraged (e.g., the new year, before spring break, or after summer vacation). Information should also be provided on general locations within the community that may serve as host sites if the individual attending the workshop does not have a site secured, as was the case for individuals in this study who were not affiliated with a worksite. Although AFAPs require a facility with a pool, AFEPs and AFSHPs may be conducted in any indoor facility (e.g., library meeting room, church hall). Leaders should be encouraged to seek out such potential host sites.

Participants also reported the types of support they preferred to receive from the state chapter of the Arthritis Foundation when adopting or maintaining AFAPs, AFEPs, or AFSHPs. Once individuals become trained leaders of AFAPs, AFEPs, or AFSHPs, fostering and maintaining a sense of connection and cohesion with the Arthritis Foundation should encourage the adoption and maintenance of programs within the community (cf. Carron \& Hausenblaus, 1998). Participants indicated that a sense of connection may be facilitated through continuing education, aid in the identification of a host site, regular certifications or recertifications, provision of standardized program promotional material, and a regular newsletter developed and distributed by the Arthritis Foundation. The latter type of support was identified in previous research as a successful marketing strategy for the recruitment of participants to AFAPs (Spencer, Kinne, Belza, Ramsey, \& Patrick, 1998). Recommendations are for the state chapters of the Arthritis Foundation to identify the most realistic and feasible strategies from those above, with particular attention to the continual use of strategies as a way to foster perceptions of connection.

Study results should be considered in view of several limitations that limit generalizability. First, participants were a small purposive sample of individuals who attended an Arthritis Foundation leader training workshop in one midwestern state. Further, the AFAP, AFEP, and AFSHP programs of focus in the study were being offered by one state's chapter of the Arthritis Foundation, and the majority of the programs were offered in urban communities. Because of the qualitative nature of this study, no causal inferences regarding perceptions of trained leaders and the reach, adoption, and maintenance of Arthritis Foundation programs could be made.

Despite these limitations, the current study expands the understanding of important issues regarding leader recruitment and retention, as well as the understanding of the reach, adoption, and maintenance of AFAPs, AFEPs, and AFSHPs. Future research should examine whether challenges to leader recruitment and retention differ between rural and urban communities. Examination of the reasons for becoming leaders among individuals of different ages (e.g., younger to middle to older adults) should also occur to aid in the development of targeted leader recruitment material. Future research should also include an examination of best practices to facilitate the reach, adoption, and maintenance of AFAPs, AFEPs, and AFSHPs between host organizations and the Arthritis Foundation. In sum, AFAPs, AFEPs, and AFSHPs are effective self-management programs that positively affect the health of adults with arthritis. With increased reach, adoption, and maintenance, as well as sufficient numbers of certified leaders, these programs may expand their positive public health impact.

\section{NOTES}

1. The list was not inclusive of all individuals who attended a leader-training workshop in the preceding 17 years because the records were not complete.

2. The state chapter of the Arthritis Foundation did not have mandatory site visits as a requirement to host an AFAP, AFEP, or AFSHP. The reason the participant believed a site visit was mandatory could not be determined through the data that were collected. 


\section{REFERENCES}

Arthritis Foundation. (1996). Arthritis Foundation YMCA aquatic program (AFYAP) and AFYAP plus. Atlanta, GA: Author.

Arthritis Foundation. (2007). Programs. Retrieved July 12, 2007, from http://www.arthritis.org/programs.php

Arthritis Foundation, Association of State and Territorial Health Officials, and Centers for Disease Control and Prevention. (1999). National Arthritis action plan: A public health strategy. Retrieved November 20, 2008, from http://www.arthritis.org/media/Delia/ NAAP_full_plan.pdf

Bopp, M., Wilcox, S., Laken, M., Hooker, S. P., Saunders, R., Parra-Medina, D., et al. (2007). Using the RE-AIM framework to evaluate a physical activity intervention in churches. Preventing Chronic Disease. Public Health Research, Practice, and Policy, 4(4), 1-9.

Boutaugh, M. L. (2003). Arthritis Foundation community-based physical activity programs: Effectiveness and implementation issues. Arthritis Care \& Research, 49(3), 463-470.

Boutaugh, M. L., \& Brady, T. J. (1996). Meeting the needs of people with arthritis. Quality of life programs of the Arthritis Foundation. Orthopaedic Nursing, 15(5), 59-80.

Carron, A. V., \& Hausenblaus, H. A. (1998). Groups dynamics in sport (2nd ed.). Morgantown, WV: Fitness Information Technology.

Estabrooks, P. A., \& Gyurcsik, N. C. (2003). Evaluating the impact of behavioral interventions that target physical activity: Issues of generalizability and public health. Psychology of Sport and Exercise, 4(1), 41-55.

Freedman, M., Hootman, J. M., \& Helmick, C. G. (2007). Projected state-specific increases in self-reported doctor-diagnosed arthritis and arthritis-attributable activity limitations: United States, 2005-2030. Morbidity and Mortality Weekly Report, 56(7), 423-425.

Glasgow, R. E., Nelson, C. C., Strycker, L. A., \& King, D. K. (2006). Using RE-AIM metrics to evaluate diabetes self-management support interventions. American Journal of Preventive Medicine, 30(1), 67-73.

Glasgow, R. E., Vogt, T. M., \& Boles, S. M. (1999). Evaluating the public health impact of health promotion interventions: The
RE-AIM framework. American Journal of Public Health, 89(9), 1322-1327.

Glazier, R. H., Bajcar, J., Kennie, N. R., \& Willson, K. (2006). A systematic review of interventions to improve diabetes care in socially disadvantaged populations. Diabetes Care, 29(7), 1675-1688.

Gyurcsik, N. C., \& Brittain, D. R. (2006). Partial examination of the public health impact of the People With Arthritis Can Exercise (PACE) program: Reach, adoption, and maintenance. Public Health Nursing, 23(6), 516-522.

Hainsworth, J., \& Barlow, J. (2001). Volunteers' experiences of becoming arthritis self-management lay leaders: "It's almost as if I've stopped aging and started to get younger!" Arthritis Care $\&$ Research, 45, 378-383.

Minor, M., Stenstrom, C. H., Klepper, S. E., Hurley, M., \& Ettinger, W. H. (2003). Work group recommendations: 2002 exercise and physical activity conference, St. Louis, Missouri. Arthritis \& Rheumatism, 49(1), 453-454.

O’Loughlin, J., Renaud, L., Richard, L., Gomez, L. S., \& Paradis, G. (1998). Correlates of the sustainability of community-based heart health promotion interventions. Preventive Medicine, 27, 702-712. Schoster, B., Callahan, L. F., Meier, A., Mielenz, T., \& DiMartino, L. (2005). The People With Arthritis Can Exercise (PACE) program: A qualitative evaluation of participant satisfaction. Preventing Chronic Disease. Public Health Research, Practice, and Policy, 2(3), 1-11.

Seguin, R. A., Economos, C. D., Hyatt, R., Palombo, R., Reed, P. N. T., \& Nelson, M. E. (2008). Design and national dissemination of the StrongWomen community strength training program. Preventing Chronic Disease. Public Health Research, Practice, and Policy, 5(1), 1-13.

Spencer, A. C., Kinne, S., Belza, B. L., Ramsey, S., \& Patrick, D. L. (1998). Recruiting adults with osteoarthritis into an aquatic exercise class: Strategies for a statewide intervention. Arthritis Care $\&$ Research, 11(6), 455-462.

Wilcox, S., Ananian, C. D., Abbott, J., Vrazel, J., Ramsey, C., Sharpe, P. A., et al. (2006). Perceived exercise barriers, enablers, and benefits among exercising and nonexercising adults with arthritis: Results from a qualitative study. Arthritis \& Rheumatism, 55(4), 616-627. 